\title{
Changes in Theta and Gamma Network Oscillations during the Development of Neurodegenerative Disorders (Review)
}

\author{
DOI: $10.17691 /$ stm2019.111.02
}

Received November 14, 2018

V.F. Kichigina, DSe, Head of the Laboratory of Systemic Organization of Neurons

Institute of Theoretical and Experimental Biophysics, Russian Academy of Sciences, 3 Institutskaya St.,

Pushchino, Moscow Region, 142290, Russia

Theta and gamma oscillations registered in the hippocampus and neocortex are necessary for cognitive processes in the brain; their alterations are revealed in many neurological and psychiatric diseases. The most common forms of neurodegenerative disorders, Alzheimer's disease (AD) and temporal lobe epilepsy (TLE) are characterized by the loss of cells and progressive violations of cognitive functions, such as memory. Early diagnosis of diseases is very important for their successful treatment. Many efforts have been done for defining early signs of these diseases. Significant advances have been made in the searching of some AD and TLE reliable biomarkers with using biochemical and imaging approaches. However, there is a great need for the biomarkers that would reflect changes of brain activity within few milliseconds to obtain information about cognitive disturbances.

In the present review, the data of recent literature specifying that the coherent analysis of the theta and gamma oscillations can be used in early diagnostics of TLE and AD are considered. These data show that in a brain with the developing neurodegenerative disorder the specific violations of the theta and gamma interaction are observed. We summarize here the data on the alterations of the theta and gamma coherence based on examples from TLE and AD and from models of these diseases. The specific disturbances in interactions of theta-gamma oscillations in hippocampal, hippocampal-entorhinal, hippocampal-prefrontal, and hippocampal-septal networks were revealed in the epileptic brain. In the AD models, marked changes were observed in the theta-gamma coupling in the subiculum, an output region of the hippocampus. In addition, a decreased theta-gamma interaction between the hippocampus and the parietal cortex as well as between the hippocampus and the prefrontal cortex was also shown

Key words: Alzheimer's disease; temporal lobe epilepsy; memory; oscillatory activity; coherent analysis; early diagnostics.

\section{Introduction}

Theta and gamma oscillations are the events related to cognitive processes. The theta rhythm (4 to $12 \mathrm{~Hz}$ ) is usually recorded in the hippocampus and surrounding limbic structures during waking and rapid eye movement sleep [1-3]. Theta oscillations have also been registered in the neocortical [4-8] and subcortical structures [9-13]. The theta rhythm is important in the formation and retrieval of episodic and spatial memory [14]. The gamma rhythm (low frequency gamma, 25-45 Hz, and high frequency gamma, $50-120 \mathrm{~Hz}$ ) usually occurs contemporary with the theta rhythm in the hippocampus [15-17]. In the neocortex, gamma oscillations mostly recorded in the frontal and parietal areas $[18,19]$. The gamma rhythm is believed to play a role in attention $[20,21]$ and in the maintenance of relevant information in memory $[22,23]$. Recent data indicating that the coupling between the phase of slow oscillations (in particular, theta) and the amplitude of fast oscillations (gamma) may be involved in information processing [24-26].

An important component of the neuronal processing underlying cognition is interaction between brain structures [27-30]. Multiple evidence point to brain rhythms as a basic mechanism of dynamical communication between brain areas; this is proved by task- and state-dependent changes in the coherence of local field potentials (LFPs) [31-37] and cross-correlated unit activity [29, 30, 38]. Synchronized activities of brain fields exert distinct effects on their ability to interact with each other [34], and provide a mechanism for the formation of cell ensembles and their coordination [30, 39-42]. The oscillations can be also considered as rhythmical changes in neuronal excitability [43, 44].

The hypothesis "communication through coherence" proposed by Pascal Fries in 2005 [44] is now widely accepted [30, 36, 45-51]. This hypothesis assumes that anatomic communications can be effective or ineffective depending on presence or lack of rhythmic synchronization $[44,52]$.

It is known that interaction of brain structures and oscillatory activity in them can disturb in psychiatric and neurological disorders [42, 53-57]. However, despite decades of research, the violations in the coherence of rhythms in pathologies, such as Alzheimer's disease (AD) and temporal lobe epilepsy (TLE) remain unclear.

This review summarizes the data on the changes of the theta and gamma coherence based on examples from TLE and $A D$ and from models of these diseases. In addition, we provided the information on some similarities and differences in these disorders, mainly in

Corresponding author: Valentina F. Kichigina, e-mail: vkitchigina@gmail.com 
the alterations of specific types of memory, parameters of theta and gamma rhythms and their coherence. These analyses may help to design new approaches to early diagnostics of pathologies.

\section{Interaction of the theta and gamma rhythms}

The brain generates many types of oscillations at different frequencies. Low-frequency rhythms are dynamically involved across distant brain areas by cognitive tasks or sensory signals; at the same time, high-frequency brain activity reflects local cortical processing [42]. External or internal stimuli can lead to the synchronization of rhythms and thus evoke a complex functional phenomenon known as phase coherence or phase coupling. The classical phase coherence reveals the relative constancy of the phase difference between two oscillations of the same frequency, i.e. within-frequency synchrony (Figure 1) $[59,60]$. It was shown that phase coupling reflects various cognitive processes in humans, monkeys, rats, and mice [25, 42, 61-66]. The within-frequency

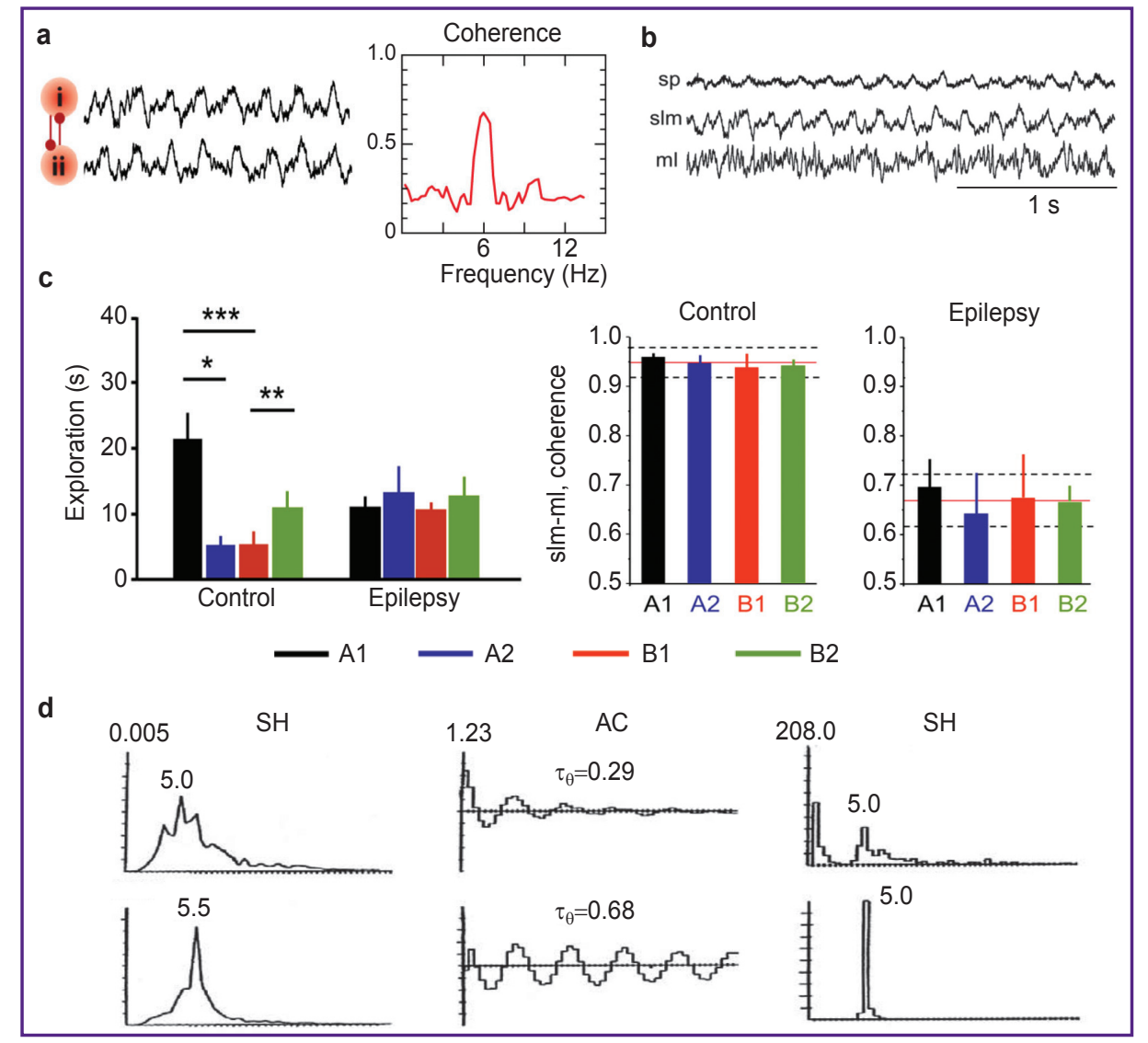

Figure 1. Changs of theta coherence between brain areas during epileptogenesis

(a) Phase-phase coupling of theta oscillations between two brain structures (i) and (ii). To the left: synthetic data used for theta rhythm illustration; to the right: coherence spectrum (or phase-specific measures) between two signals can determine the strength of theta phase coupling. (b) Representative hippocampal activity of an epileptic rat recorded in the stratum pyramidale $(\mathrm{sp})$, lacunosum moleculare $(\mathrm{slm})$, and moleculare $(\mathrm{ml})$ during walking. (c) Behavioral data for rats during the performance of the episodic-like memory task; distribution of exploratory times per object in the test phase for the control and epileptic groups is shown. The objects shown in the task: A1 - old familiar stationary object, A2 - old familiar displaced, B1 - recent (i.e. shown 50 min later) familiar stationary, B2 - recent familiar displaced object; ${ }^{*} p<0.05,{ }^{* *} p<0.01,{ }^{* * *} p<0.005$. Phase theta coherence between hippocampal layers ( $\mathrm{sml}$ and $\mathrm{ml}$ ) during exploration of each individual object in the episodic-like memory task; the mean values of theta coherence per object within the mean (red line) and standard deviation (dashed line) for the whole session in the control (left) and epileptic animals (right) are shown. It can be seen that theta coherence between hippocampal layers is high in the rat control group but significantly lower in the epileptic group. (d) Theta activity increases synchronously in the hippocampus and medial septal-diagonal band complex (MSDB) before seizures. From left to the right: spectral histograms $(\mathrm{SH})$ for hippocampal local field potentials; autocorrelograms (AC) and SH for neuronal activity of MSDB; above - background, below - before seizures. On SH: the ordinate axis - spectral density (relative units); the abscissa axis - frequency, from 0.5 to $30 \mathrm{~Hz}$; on AC: the ordinate axis - the value of the decay time constant of the rhythmic process ( $\tau$ or rhythm index) (s); the abscissa axis - time, from 0 to $1 \mathrm{~s}$. Adapted with permission from Buzsáki, Watson, 2012 [42] (a); Inostroza et al., 2013 [56] (b), (c); Kitchigina, Butuzova, 2009 [58] (d) 
phase coherence between oscillations in different brain areas (Figure 1 (a)) was studied extensively because of its proposed role in the regulation of inter-structural communications [34, 67-70].

Besides, the correlation between the amplitude envelopes of two brain waves at different frequencies, called cross-frequency amplitude-amplitude coupling, is also an oscillatory characteristic [71, 72]; this type of coupling was observed by some authors [71-74], but despite correlations with behavior, its functional role remains poorly understood.

The phase coupling between theta and gamma oscillations, namely, the phase-amplitude crossfrequency coupling (CFC) [7, 15, 22, 25, 64, 66, 75-83] and the phase-phase CFC in which several gamma cycles are entrained within one cycle of theta [84-88] are the most studied phenomena of phase coherence. The phase-amplitude CFC describes the dependence between the phase of the low-frequency rhythm and the amplitude of the high-frequency oscillations [24] (Figure 2). Thus, it reflects the interrelations between local microscale $[49,90]$ and system-level macroscale neuronal networks [24, 78, 91].

The case when the phase of slower oscillations modulates the amplitude of a faster rhythm (or rhythms) is probably the most prominent 'law' underlying the hierarchy of the system of brain oscillators [15, 92, 93]. Thus, phase-amplitude CFC can be used as an index of cortical excitability and network interactions [94-96]. In non-epileptogenic hippocampi of neurosurgical patients and in a healthy brain of rodents, the degree of theta-gamma phase-amplitude coupling increases with learning [25, 64, 97]. In the hippocampus, gamma and theta oscillations normally show a marked phaseamplitude CFC considered to be central to hippocampal functions [25, 64, 98]. Thus, during spatial learning, the strength of hippocampal theta-gamma coupling usually directly correlated with the increase in correct performance of a cognitive task [25].

At the same time, phase-phase CFC provides, as believed, a physiological mechanism for the linkage of the activity generated at significantly different rates. Since gamma oscillations are faster than theta ones, numerous cycles of gamma arise during a single cycle of theta (Figure 2 (a), (b)). The phenomenon of phase-phase theta-gamma coupling means that gamma waves always begin at the same phase of theta waves. Phase-phase CFC was hypothesized to take part in cognitive processes, such as attention and memory [22, 71, 78, 99, 100]. An influential model in which theta and gamma oscillations would interact to produce a neural code (" $7 \pm 2$ short-term memories"), in which several gamma cycles are entrained within one cycle of theta has been proposed a decade ago [78] Latest findings show that this mechanism indeed is used by the hippocampus [85-88]. It is assumed that the temporal coordination of neuronal spikes by phasephase theta-gamma coupling may improve transferring information as well as spike-timing-dependent plasticity [100-102]. Desynchronization of these rhythms could be altered in certain neurodegenerative pathologies.

\section{Disturbances of theta-gamma coherence are typical for Alzheimer's disease and temporal lobe epilepsy}

Alterations in rhythm coherence in the epileptic brain. Epilepsy, a disorder associated with increased network excitability and neuron loss, is usually accompanied by rewiring in the brain (for review, see [103]). TLE is the most common and pharmacologically resistant type of adult focal epilepsy. In patients with TLE, selective and marked degradation of episodic (autobiographic) memory was shown, in which specific memory items are placed within temporal context during encoding and retrieval [104]. Animals with TLE also exhibited a highly specific impairment of the episodiclike memory while mostly preserving other forms of hippocampal-dependent memories [105-107].

Hippocampal network. The analysis of hippocampal LFPs in neurosurgical patients during the execution of episodic memory tasks revealed a sharp increase of gamma oscillations in non-epileptogenic hippocampi before successful item encoding. At the same time, the epileptogenic hippocampi exhibited a significant decrease in the gamma band power, which predicts successful item encoding $[97,108]$. Thus, typical changes in the gamma band power during this process are reversed for human epileptogenic hippocampus [108] Besides, it was shown in the TLE model [56] that kainatetreated rats with deficit of episodic-like memory exhibited reduction of hippocampal theta power and coherence along the CA1-dentate axis. In TLE animals, decreased theta coherence in the LFP signals was concentrated between the hippocampal stratum lacunosum-moleculare and moleculare of dentate gyrus (DG) (Figure 1 (b), (c)). Inostroza and colleagues [56] believe that these data point to discoordination of hippocampal inputs from layers III and II of the entorhinal cortex (EC) and from the contralateral hippocampus as a possible cause for dysfunction of episodic-like memory in TLE animals.

Hippocampal-entorhinal cortex network. It is known that a crucial mechanism of episodic memory is the coherence of neuronal activity in the hippocampalentorhinal circuit; this mechanism is usually impaired in TLE [105]. An alteration of theta coherence between the EC and the DG was revealed in behaving kainateinjected epileptic mice during the interictal phase [54]. Indeed, in epileptic mice, the theta activity in the EC was delayed with respect to that of the DG, while the theta activity in healthy animals was synchronized between $E C$ and DG, demonstrating the within-frequency phase coupling. On the basis of a computational neural mass model, the authors suggested that hippocampal cell loss destroyed the coupling of the subnetworks, which induced the EC-DG shift [54]. 


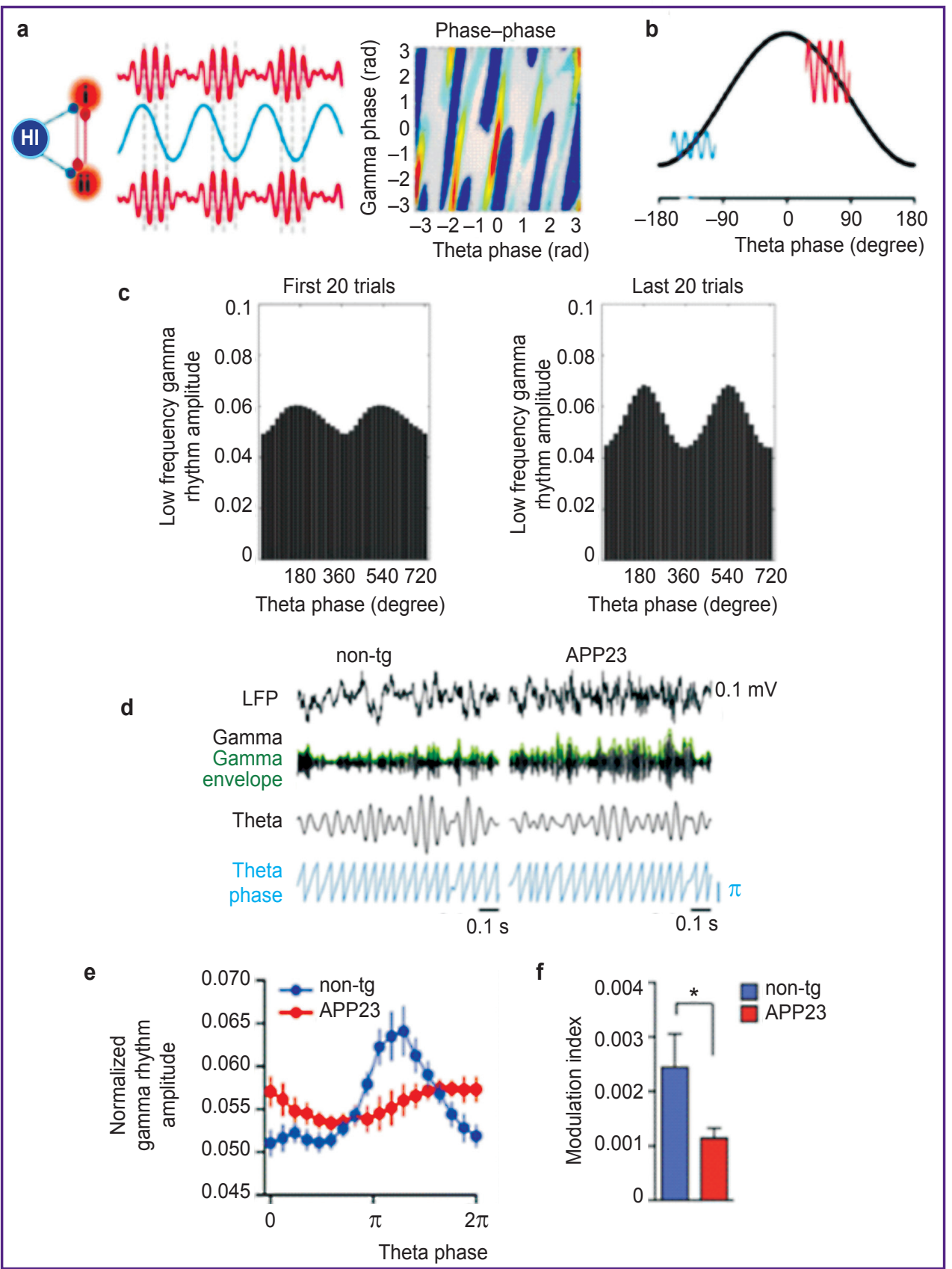

Figure 2. Theta-gamma cross-frequency coherence and its alteration in a rat Alzheimer's model

(a) Schematic illustration of cross-frequency phase-phase coupling. Phases of theta and gamma oscillations are correlated, as shown on the right by the phase-phase plot of the two frequencies; (i) and (ii) - different brain areas, Hi - hippocampus. (b) A schematic model of cross-frequency phase-amplitude coupling. Gamma oscillations are large in the excitatory phase of theta wave (near to the top) and small in the inhibitory phase of theta wave (near to the trough). (c) Amplitude of gamma oscillations in the hippocampal CA3 field increases with learning; the distribution of gamma amplitudes is shown depending on the phase of the theta wave during the first twenty samples (left) and during the last twenty samples (right). (d) Top-down: original local field potentials (LFP), filtered theta $(4-12 \mathrm{~Hz})$ and gamma $(25-100 \mathrm{~Hz})$ oscillations, gamma-wave envelope, theta phase in APP23 (tg) and normal (non-tg) rats; representative signals from 5 animals of each genotype are presented. (e) Phase-amplitude plot (gamma amplitude modulation by theta wave phase) computed for hippocampal LFPs recorded in control and APP23 (tg) mice. (f) Modulation index computed for the phase-amplitude distributions shown in (e); ${ }^{*} p<0.05$. Adapted with permission from Buzsáki, Watson, 2012 [42] (a); Kirihara et al., 2012 [53] (b); Tort et al., 2009 [25] (c); Ittner et al., 2014 [89] (d)-(f)

In experiments with healthy rats, the inputs from the medial and lateral EC (via temporoammonic and perforant inputs) evoked a firing of hippocampal neurons, which reflects an integrated representation of spatial and temporal information [109-113] as well as new experience $[114,115]$. This neuronal coding is precisely 
organized within a time scale, which is controlled by ongoing oscillations, especially by the hippocampal theta and gamma rhythms [2, 14, 26, 116-119]. A careful measurement of the proximodistal coherence of the theta activity in the dorsal hippocampus of normal and epileptic animals showed that healthy rats exhibited a stronger coordination between the temporoammonic and perforant entorhinal inputs near CA3 field (at proximal locations), while epileptic rats showed stronger coordination near subiculum (at distal locations) [57]. This opposing trend in epileptic rats was associated with the connectivity constraint, which accompanies cell death in the hippocampus. Laurent et al. [57] also discovered that the appropriate timing between entorhinal inputs arriving over several theta cycles at the proximal and distal ends of the dorsal hippocampus was impaired in epileptic rats. It is important that the computational reconstruction of LFP signals predicted that timing variability has a major impact on repairing theta coherence. Thus, the proximodistal organization of entorhinal inputs plays an important role in temporal lobe physiology, and this organization alters during TLE [57].

Hippocampal-medial prefrontal cortex network. As was mentioned above, experiments with healthy animals showed that theta and gamma oscillations are usually present and work in synchrony in the hippocampus and medial prefrontal cortex (mPFC) during the performance of cognitive tasks [19, 64]. Hippocampal theta oscillations are normally coupled to mPFC theta waves [19] and modulate hippocampal and mPFC gamma oscillations during cognitive behavior [64, 120, 121]. In a TLE model generated by perforant path stimulation, abnormal changes in the hippocampalmPFC circuit were observed during the recording of mPFC and hippocampal LFPs in rats with spontaneous recurrent seizures [122]. Broggini and colleagues [122] showed that recurrent seizures weaken hippocampal theta rhythm while the hippocampal and mPFC theta coherence increases during a period preceding the onset of seizures. Simultaneously with the increase in theta synchrony a stronger coupling between hippocampal theta and mPFC gamma oscillations was observed. Using the Granger causality, it was shown that the increase in hippocampus-mPFC synchrony in the preictal phase was provoked by hippocampal networks. The data indicate that the increase in hippocampalmPFC coherence may predict the seizure onset [122]. Besides, the too strong coupling of hippocampal theta and mPFC gamma oscillations may induce abnormal plasticity in mPFC communications [86].

Hippocampal-septal network. The registration of LFPs in the hippocampus and medial septaldiagonal band complex (MSDB) of rats and guinea pigs revealed that normally theta oscillations were relatively synchronous in these brain regions $[10,13,36]$. Usually, theta power in the MSDB was smaller compared to that in the hippocampus, but the frequency of theta oscillations, although it did not coincide in these structures, did not differ significantly. The theta coherence between the hippocampus and MSDB was relatively high: a phase analysis revealed no clear unidirectional shifts $(<10 \mathrm{~ms})$ in the hippocampal and MSDB theta phases in healthy animals $[10,13]$. In chronic epileptic animals, a significant decrease of the theta power was revealed in the hippocampus [36, 123-126] and MSDB [13]. In addition, in a pilocarpine rat model of TLE, a dysfunctional and uncoupled septohippocampal network was revealed [127]. However, in the perforant path kindling model of TLE, some increase in synchronization between hippocampus and MSDB within the theta band was observed in waking guinea pigs during epileptogenesis [13]. Besides, in this model of TLE, a dramatic increase of the theta oscillations simultaneously in the rabbit hippocampus and MSDB before (within 20 s) the seizures was observed [58]. This phenomenon reminds the events in the hippocampal-mPFC network over time prior to seizure onset in rats in the same model of TLE [122]. Interestingly, in the perforant path kindling model of TLE in guinea pigs, the interactions between the hippocampus and MSDB changed for opposite during epileptogenesis: at the beginning of kindling, the MSDB was ahead in the theta phase, but after formation of the pathological focus, MSDB lagged the hippocampus [13]. In addition, the relationships between rhythmic bursts of septal neurons and the phases of the hippocampal theta waves during spontaneous seizures in rabbits with TLE model could reverse to almost opposite comparative to interictal ones [58], i.e, these relationships were not constants.

\section{Alterations in the rhythm coherence in Alzheimer's} disease and in the Alzheimer's disease models

Disturbances of theta and gamma rhythms in brain with $A D$ pathology. $A D$ is a progressive neurodegenerative disease associated with an irreversible deterioration of cognitive functions, especially memory. Although the etiology of $A D$ remains unknown and now there is no reliable treatment, a consensus has emerged early in this century on the amyloid hypothesis $[128,129]$, which posits that the amyloid $\beta(A \beta)$ peptide, a major constituent of amyloid plaques, is mostly responsible for the alteration of cognitive functions [129, 130]. In the last years, however, this hypothesis was challenged: a potential role of metabolism impairment of amyloid precursor protein (APP) and its progress through tau pathology were considered in the etiology of $A D$ (for review, see [131]). Moreover, the recent data of experiments with wild-type and APP/PS1 transgenic mice indicate that amyloid plaques can possess capacity for binding additional $A \beta$ [132].

Various forms of memory are disturbed in $A D$ [133]. It has been assumed that navigation deficits can help to separate individuals at higher risk of developing $A D$ from patients with other neurodegenerative diseases [134]. As it was revealed in some works, $A D$ patients, as opposed to healthy age-matched control subjects, exhibit an increase in the relative power of slow oscillations (in particular, theta rhythm) and a decrease in the relative 
power of fast oscillations (gamma rhythm) [135-139]. On the contrary, in other works, an increased gamma rhythm power and the lack of theta increase in $A D$ patients were reported [140,141]. Some authors noted that changes in EEG of resting $A D$ patients might not be specific, and various types of dementia can also exhibit similar network disturbances [136]. Besides, contrary to the data on $A D$ patients, a decrease of both theta and gamma bands was revealed in Tg5xFAD mice, a transgenic mouse model of $A D$; in this case, the decrease preceded alterations in learning performances in spatial task [142]. In addition, transgenic APP23 mice, another mouse model of $A D$, demonstrated the compromised spectral contributions of hippocampal theta and gamma oscillations, compared to nontransgenic controls: a markedly lower spectral power of theta oscillations $(\sim 10 \mathrm{~Hz})$ and a higher power of gamma oscillations (25$50 \mathrm{~Hz}$ ) [89], changes opposite to those in AD patients. Hence, a decrease or an increase in theta and gamma oscillations power per se may not be specific for this pathology [136].

Alterations in theta-gamma coherence are indicative for brain with $A D$ pathology. Probably, most convincing evidence of rhythm disturbances in a pathological AD brain is alterations in the theta-gamma CFC. Thus, in humans with $A D$, an enhanced CFC between the gamma and low-frequency bands (in particular, theta) compared to healthy control was revealed [141]. During performance of working memory tasks, evidence for a relationship between altered theta-gamma coupling and working memory deficits in individuals with $A D$ was obtained [143].

In the AD model (adult APP23 transgenic free-roaming mice), an impairment of cross-frequency gamma amplitude modulation by hippocampal theta rhythm was observed [89] (Figure 2 (c), (d)). It is important that these changes were observed before the onset of $A \beta$ plaque pathology. Moreover, it was shown on TgCRND8 mice that a significant proportion of 1-month-old animals exhibited marked alterations in the theta-gamma coupling in the output region of the hippocampus, the subiculum. This uncoupling of rhythms arises before any histopathological abnormalities such as the presence of amyloid plaques [144]. In addition, it was shown that 1-month-old TgCRND8 mice expressed extremely low levels of $A \beta$ compared to controls. Goutagny et al. [144] suggested that in animals (TgCRND8 mice) disturbed theta-gamma CFC in the subiculum may be the earliest detectable AD-related biomarker. This is in contrast with the existing hypothesis, which states that the beginning of hippocampal network alterations and memory deficits in animal models of $A D$ are caused by the overproduction of soluble $A \beta[129,130,145]$.

Interestingly, though APP is supposed to be critically involved in the pathophysiology of $A D$, APP-deficient mice exhibit cognitive deficits [146, 147]; this confirms that APP plays an important role in the functioning of neurons in the healthy brain. Recently, strongly diminished theta-gamma coupling in LFPs from the dorsal hippocampus and parietal cortex was revealed in APP knockout mice. Besides, cross-regional hippocampal-prefrontal CFC was largely disrupted in these knockout mice [148]. This effect may be of importance for the origination of cognitive deficits in APP-deficient animals. Thus, APP is important for the interaction of rhythms of different frequencies. The facts mentioned above possibly indicate, that there exists very thin frontier between functioning of APP in the healthy and pathological brains.

Quite recently, it has been tested whether a preclinical $A D$ pathologic feature, tau aggregation in the EC, can disrupt the coordination of LFPs between its two efferent regions, the hippocampus and prelimbic mPFC [73]. Tanninen and colleagues [73] revealed strengthened phase-phase and amplitude-amplitude couplings of theta and gamma oscillations in these two regions during associative learning in healthy rats. In tauexpressing rats, the hippocampus and prefrontal cortex showed a significant attenuation of stimulus-evoked theta oscillations. In addition, despite normal memory acquisition, the learning-related oscillatory coupling between the hippocampus and the prefrontal cortex in these rats was diminished; at the same time, the entorhinal tau overexpression enhanced the stimulusevoked theta-gamma phase-amplitude coupling within the mPFC. The authors suggested that the tau aggregation in the EC caused aberrant long-range circuit activity during associative learning, indicating the disturbances in neural oscillations of preclinical $A D$ stages [73].

\section{Similarities and differences in brain disorders with neuropathologies peculiar \\ for Alzheimer's disease and temporal lobe epilepsy}

Similarities in the alterations of oscillatory activity in the AD/TLE brain (in particular, disturbances in thetagamma coherence in hippocampal-neocortical networks) suggests that these diseases have some common properties and, probably, at least partially similar mechanisms of their development.

The potential relation between TLE and AD has been supported by experimental and clinical data. Thus, aging is a common and well-established risk factor for epilepsy and AD [149-153]. Besides, AD may be an important cause of epileptic disorders, as shown in elderly humans [149, 154-156] and in animals with AD models [153, 157]. Patients with AD have a five- to tenfold increased risk of the development of seizures or other forms of epileptiform activity [150]. Although seizure pathology was previously believed to be secondary to $A D$, it was found that neuronal activity can regulate regional vulnerability to $A \beta[129,158,159]$; in particular, enhanced neuronal excitability can increase $A \beta$ generation [160]. Moreover, disturbed activity may 
contribute to the development of cognitive violations: epileptiform and rhythmic abnormalities in the temporal regions (in particular in the hippocampus) can cause amnestic disorders, which were reduced by antiepileptic drug treatment [55, 161]. In patients with seizures in combination with $A D$, a case series from California with so-called vu/déjà vu phenomena was described [162], while another series from France [163] had some cases that were termed "epileptic prodromal AD". The authors believed that there is an epileptic version of $A D$, which usually starts with seizures as an initial symptom followed by cognitive deficit. Similar signs of cognitive and behavioral impairments in TLE and AD have been recently described by Chin and Scharfman [164].

Abundant clinical evidence indicates to increased comorbidity of seizure pathology in $A D$ : it is becoming clear that $A D$ is associated with neuronal hyperexcitability as well as network hypersynchronicity, which is the main reasons of epilepsy development [165-168]. Indeed, epileptic prodromal AD patients suffer from seizures sometimes even before developing clear cognitive disorders. The epileptiform activity may manifest itself in the early stages of $A D$ more often than was previously proposed. Thus, seizures in patients with $A D$ and amnestic mild cognitive impairment are associated with an earlier appearance of cognitive decline [150, 162, 169, 170].

At the same time, neurodegenerative processes peculiar to dementia can play a central role in the development of epilepsy in the patients predisposed to cognitive deficit. Adult-onset epilepsy of unknown cause could thus represent a risk factor for the ongoing neurodegenerative damage, even when epileptic manifestations and clinically recognized dementia are separated by long time [171].

In the hippocampus, one of the main foci of cell death in TLE and AD brains, the network hypersynchronicity and epileptiform activity can be the result of formation of extensive aberrant neuronal connections. This aberrant remodeling was revealed in epileptic rats and in APP transgenic mice [39, 129, 158, 172, 173]. The aberrant reconstruction can be a cause of alterations in the oscillatory activity and rhythm coherence in brains with TLE and AD pathologies.

\section{Conclusions}

The main difficulties in diagnosis of neurodegenerative diseases are the detection of neuronal abnormalities at early stages of their development. Now significant achievements have been made in the development of methods for the detection of some biomarkers of $A D$ and TLE, including cerebrospinal fluid and plasma measurements and glucose positron emission tomography. However, there is an urgent need for biomarkers that would reflect changes in brain functioning within few milliseconds to obtain information about the progressing cognitive deficiency [174]. The application of magnetoencephalography [175] in combination with the coherent analysis, in particular during cognitive loading, is a promising approach to early diagnosis of these diseases. Thus, the specific disturbances in interactions of theta-gamma oscillations in hippocampal, hippocampalentorhinal, hippocampal-prefrontal, and hippocampalseptal networks were revealed in the epileptic brain. In the $A D$ models, marked changes were observed in the theta-gamma coupling in the subiculum, an output region of the hippocampus. Besides, a decreased theta-gamma coupling between the hippocampus and the parietal cortex as well as between the hippocampus and the prefrontal cortex was also shown.

Possibly, in future, specific disturbances in thetagamma coherence will serve as markers of particular cell damage and will allow one to direct therapeutic influences to certain neural loci at early stages of the development of the disease.

Acknowledgments. The author is grateful to S.V. Sidorova for help in preparing the manuscript.

Study funding. This work was supported by the Russian Foundation for Basic Research (grant number 18-015-00157-a) and the grant provided jointly by the Russian Foundation for Basic Research and the Ministry of Investments and Innovations of the Moscow region (grant number 17-44-500312 p_a).

Conflicts of interest. The authors have no conflicts of interest to disclose.

\section{References}

1. Vanderwolf C. Hippocampal electrical activity and voluntary movement in the rat. Electroencephalogr Clin Neurophysiol 1969; 26(4): 407-418, https://doi.org/10. 1016/0013-4694(69)90092-3.

2. Bland B.H. The physiology and pharmacology of hippocampal formation theta rhythms. Prog Neurobiol 1986; 26(1): 1-54, https://doi.org/10.1016/0301-0082(86)90019-5.

3. Buzsáki G. Theta oscillations in the hippocampus. Neuron 2002; 33(3): 325-340, https://doi.org/10.1016/s08966273(02)00586-x.

4. Klimesch W., Doppelmayr M., Schimke H., Ripper B. Theta synchronization and alpha desynchronization in a memory task. Psychophysiology 1997; 34(2): 169-176, https:// doi.org/10.1111/j.1469-8986.1997.tb02128.x.

5. Kahana M.J., Sekuler R., Caplan J.B., Kirschen M., Madsen J.R. Human theta oscillations exhibit task dependence during virtual maze navigation. Nature 1999; 399(6738): $781-$ 784, https://doi.org/10.1038/21645.

6. Jensen O., Tesche C.D. Frontal theta activity in humans increases with memory load in a working memory task. Eur J Neurosci 2002; 15(8): 1395-1399, https://doi.org/10.1046/ j.1460-9568.2002.01975.x.

7. Vinogradova O.S. Expression, control, and probable functional significance of the neuronal theta-rhythm. Prog Neurobiol 1995; 45(6): 523-583, https://doi.org/10.1016/03010082(94)00051-i.

8. Guderian S., Schott B.H., Richardson-Klavehn A., Duzel E. Medial temporal theta state before an event predicts episodic encoding success in humans. Proc Natl Acad Sci 
U S A 2009; 106(13): 5365-5370, https://doi.org/10.1073/ pnas.0900289106.

9. Paré D. Amygdala oscillations and the consolidation of emotional memories. Trends Cogn Sci 2002; 6(7): 306-314, https://doi.org/10.1016/s1364-6613(02)01924-1.

10. Nerad L., McNaughton N. The septal EEG suggests a distributed organization of the pacemaker of hippocampal theta in the rat. Eur J Neurosci 2006; 24(1): 155-166, https://doi. org/10.1111/j.1460-9568.2006.04902.x.

11. Magill P.J., Sharott A., Bolam J.P., Brown P. Delayed synchronization of activity in cortex and subthalamic nucleus following cortical stimulation in the rat. J Physiol 2006; 574(3): 929-946, https://doi.org/10.1113/jphysiol.2006.110379.

12. DeCoteau W.E., Thorn C., Gibson D.J., Courtemanche R., Mitra P., Kubota Y., Graybiel A.M. Learningrelated coordination of striatal and hippocampal theta rhythms during acquisition of a procedural maze task. Proc Natl Acad Sci U S A 2007; 104(13): 5644-5649, https://doi.org/10.1073/ pnas.0700818104.

13. Kabanova I.V., Sinelnikova V.V., Popova I.Y., Kichigina V.F., Aliev R.R. Coherence and phase analysis of theta oscillations in the septohippocampal system during generation of convulsive activity. Neurosci Behav Physi 2013; 43(2): 214-218, https://doi.org/10.1007/s11055-013-9716-1.

14. Hasselmo M.E., Bodelón C., Wyble B.P. A proposed function for hippocampal theta rhythm: separate phases of encoding and retrieval enhance reversal of prior learning. Neural Comput 2002; 14(4): 793-817, https://doi.org/10.1162/ 089976602317318965.

15. Bragin A., Jando G., Nadasdy Z., Hetke J., Wise K., Buzsaki G. Gamma $(40-100 \mathrm{~Hz})$ oscillation in the hippocampus of the behaving rat. J Neurosci 1995; 15(1): 47-60, https://doi. org/10.1523/jneurosci.15-01-00047.1995.

16. Strogatz S.H. Nonlinear dynamics and chaos: with applications to physics, biology, chemistry and engineering. Cambridge, MA: Perseus Books; 2003.

17. Buzsáki G., Wang X.-J. Mechanisms of gamma oscillations. Annu Rev Neurosci 2012; 35(1): 203-225, https:// doi.org/10.1146/annurev-neuro-062111-150444.

18. Bouyer J., Montaron M., Rougeul A. Fast frontoparietal rhythms during combined focused attentive behaviour and immobility in cat: cortical and thalamic localizations. Electroencephalogr Clin Neurophysiol 1981; 51(3): 244-252, https://doi.org/10.1016/0013-4694(81)90138-3.

19. Benchenane K., Peyrache A., Khamassi M., Tierney P.L., Gioanni Y., Battaglia F.P., Wiener S.I. Coherent theta oscillations and reorganization of spike timing in the hippocampal-prefrontal network upon learning. Neuron 2010; 66(6): 921-936, https://doi.org/10.1016/j.neuron.2010. 05.013.

20. Fries P. Neuronal gamma-band synchronization as a fundamental process in cortical computation. Annu Rev Neurosci 2009; 32(1): 209-224, https://doi.org/10.1146/ annurev.neuro.051508.135603.

21. Jutras M.J., Fries P., Buffalo E.A. Gamma-band synchronization in the macaque hippocampus and memory formation. J Neurosci 2009; 29(40): 12521-12531, https://doi. org/10.1523/jneurosci.0640-09.2009.

22. Sauseng P., Klimesch W., Heise K.F., Gruber W.R., Holz E., Karim A.A., Glennon M., Gerloff C., Birbaumer N., Hummel F.C. Brain oscillatory substrates of visual short-term memory capacity. Curr Biol 2009; 19(21): 1846-1852, https:// doi.org/10.1016/j.cub.2009.08.062.
23. Sridharan D., Knudsen E.I. Gamma oscillations in the midbrain spatial attention network: linking circuits to function. Curr Opin Neurobiol 2015; 31: 189-198, https://doi. org/10.1016/j.conb.2014.11.006.

24. Canolty R.T., Knight R.T. The functional role of crossfrequency coupling. Trends Cogn Sci 2010; 14(11): 506-515, https://doi.org/10.1016/j.tics.2010.09.001.

25. Tort A.B.L., Komorowski R.W., Manns J.R., Kopell N.J., Eichenbaum $\mathrm{H}$. Theta-gamma coupling increases during the learning of item-context associations. Proc Natl Acad Sci 2009; 106(49): 20942-20947, https://doi.org/10.1073/ pnas.0911331106.

26. Lisman J.E., Jensen O. The theta-gamma neural code. Neuron 2013; 77(6): 1002-1016, https://doi.org/10.1016/j. neuron.2013.03.007.

27. Livanov M.N., Krylov V.Yu., Ostrjakova T.V., Shulgina G.I. Slow field potential oscillations as one of the basic mechanisms of integrative activity of neurons [proceedings]. Act Nerv Super (Praha) 1977; 19(1): 43-44.

28. Vinogradova O.S. Hippocampus as comparator: role of the two input and two output systems of the hippocampus in selection and registration of information. Hippocampus 2001; 11(5): 578-598, https://doi.org/10.1002/hipo.1073.abs.

29. Engel A.K., Fries P., Singer W. Dynamic predictions: oscillations and synchrony in top-down processing. Nat Rev Neurosci 2001; 2(10): 704-716, https://doi. org/10.1038/35094565.

30. Igarashi K.M., Lu L., Colgin L.L., Moser M.-B., Moser E.I. Coordination of entorhinal-hippocampal ensemble activity during associative learning. Nature 2014; 510(7503): 143-147, https://doi.org/10.1038/nature13162.

31. Fell J., Klaver P., Lehnertz K., Grunwald T., Schaller C., Elger C.E., Fernández G. Human memory formation is accompanied by rhinal-hippocampal coupling and decoupling. Nat Neurosci 2001; 4(12): 1259-1264, https://doi.org/10.1038/ nn759.

32. Varela F., Lachaux J.-P., Rodriguez E., Martinerie J. The brainweb: phase synchronization and large-scale integration. Nat Rev Neurosci 2001; 2(4): 229-239, https://doi. org/10.1038/35067550.

33. Buzsáki G. Large-scale recording of neuronal ensembles. Nat Neurosci 2004; 7(5): 446-451, https://doi. org/10.1038/nn1233.

34. Womelsdorf T., Fries P., Mitra P.P., Desimone R. Gamma-band synchronization in visual cortex predicts speed of change detection. Nature 2005; 439(7077): 733-736, https:// doi.org/10.1038/nature04258.

35. Vinck M., Bos J.J., Van Mourik-Donga L.A., Oplaat K.T., Klein G.A., Jackson J.C., Gentet L.J., Pennartz C.M. Celltype and state-dependent synchronization among rodent somatosensory, visual, perirhinal cortex, and hippocampus CA1. Front Syst Neurosci 2016; 9: 187, https://doi.org/10.3389/ fnsys.2015.00187.

36. Astasheva E.V., Kitchigina V.F. Activation of the glutamatergic system of the medial septal area accelerates epileptogenesis. Neurosci Behav Physi 2011; 41(3): 316-320, https://doi.org/10.1007/s11055-011-9418-5.

37. Bott J.B., Muller M.A., Jackson J., Aubert J., Cassel J.C., Mathis C., Goutagny R. Spatial reference memory is associated with modulation of theta-gamma coupling in the dentate gyrus. Cereb Cortex 2015; 26(9): 3744-3753, https:// doi.org/10.1093/cercor/bhv177.

38. Tabuchi E.T., Mulder A.B., Wiener S.I. Position 
and behavioral modulation of synchronization of hippocampal and accumbens neuronal discharges in freely moving rats. Hippocampus 2000; 10(6): 717-728, https://doi.org/10.1002/1098-1063(2000)10:6<717::aidhipo1009>3.0.co;2-3.

39. Harris K.D., Csicsvari J., Hirase H., Dragoi G., Buzsáki G. Organization of cell assemblies in the hippocampus. Nature 2003; 424(6948): 552-556, https://doi. org/10.1038/nature01834.

40. Colgin L.L., Moser E.I. Gamma oscillations in the hippocampus. Physiology 2010; 25(5): 319-329, https://doi. org/10.1152/physiol.00021.2010.

41. Buzsáki G. Neural syntax: cell assemblies, synapsembles, and readers. Neuron 2010; 68(3): 362-385, https://doi.org/10.1016/j.neuron.2010.09.023.

42. Buzsáki G., Watson B.O. Brain rhythms and neural syntax: implications for efficient coding of cognitive content and neuropsychiatric disease. Dialogues Clin Neurosci 2012; 14(4): 345-367.

43. Volgushev M., Chistiakova M., Singer W. Modification of discharge patterns of neocortical neurons by induced oscillations of the membrane potential. Neuroscience 1998; 83(1): 15-25, https://doi.org/10.1016/s0306-4522(97)00380-1.

44. Fries P. A mechanism for cognitive dynamics: neuronal communication through neuronal coherence. Trends Cogn Sci 2005; 9(10): 474-480, https://doi.org/10.1016/j. tics.2005.08.011.

45. Jensen O., Kaiser J., Lachaux J.-P. Human gammafrequency oscillations associated with attention and memory. Trends Neurosci 2007; 30(7): 317-324, https://doi. org/10.1016/j.tins.2007.05.001.

46. Mitchell D.J., McNaughton N., Flanagan D., Kirk I.J. Frontal-midline theta from the perspective of hippocampa "theta". Prog Neurobiol 2008; 86(3): 156-185, https://doi. org/10.1016/j.pneurobio.2008.09.005.

47. Rutishauser U., Ross I.B., Mamelak A.N., Schuman E.M. Human memory strength is predicted by thetafrequency phase-locking of single neurons. Nature 2010; 464(7290): 903-907, https://doi.org/10.1038/nature08860.

48. Wang X.-J. Neurophysiological and computational principles of cortical rhythms in cognition. Physiol Rev 2010; 90(3): 1195-1268, https://doi.org/10.1152/physrev. 00035.2008.

49. Colgin L.L., Denninger T., Fyhn M., Hafting T., Bonnevie T., Jensen O., Moser M.B., Moser E.I. Frequency of gamma oscillations routes flow of information in the hippocampus. Nature 2009; 462(7271): 353-357, https://doi. org/10.1038/nature08573

50. Colgin L.L. Oscillations and hippocampal-prefrontal synchrony. Curr Opin Neurobiol 2011; 21(3): 467-474, https:// doi.org/10.1016/j.conb.2011.04.006.

51. Colgin L.L. Theta-gamma coupling in the entorhinalhippocampal system. Curr Opin Neurobiol 2015; 31: 45-50, https://doi.org/10.1016/j.conb.2014.08.001.

52. Bastos A.M., Vezoli J., Fries P. Communication through coherence with inter-areal delays. Curr Opin Neurobiol 2015; 31: 173-180, https://doi.org/10.1016/j.conb.2014.11.001.

53. Kirihara K., Rissling A.J., Swerdlow N.R., Braff D.L., Light G.A. Hierarchical organization of gamma and theta oscillatory dynamics in schizophrenia. Biol Psychiatry 2012; 71(10): 873-880, https://doi.org/10.1016/j.biopsych.2012.01.016.

54. Froriep U.P., Kumar A., Cosandier-Rimélé D. Häussler U., Kilias A., Haas C.A., Egert U. Altered theta coupling between medial entorhinal cortex and dentate gyrus in temporal lobe epilepsy. Epilepsia 2012; 53(11): 1937-1947, https://doi.org/10.1111/j.1528-1167.2012.03662.x.

55. Bakker A., Krauss G.L., Albert M.S., Speck C.L., Jones L.R., Stark C.E., Yassa M.A., Bassett S.S., Shelton A.L., Gallagher M. Reduction of hippocampal hyperactivity improves cognition in amnestic mild cognitive impairment. Neuron 2012; 74(3): 467-474, https://doi. org/10.1016/j.neuron.2012.03.023.

56. Inostroza M., Brotons-Mas J.R., Laurent F., Cid E., de la Prida L.M. Specific impairment of "what-where-when" episodic-like memory in experimental models of temporal lobe epilepsy. J Neurosci 2013; 33(45): 17749-17762, https://doi. org/10.1523/jneurosci.0957-13.2013.

57. Laurent F., Brotons-Mas J.R., Cid E., Lopez-Pigozzi D. Valero M., Gal B., de la Prida L.M. Proximodistal structure of theta coordination in the dorsal hippocampus of epileptic rats. J Neurosci 2015; 35(11): 4760-4775, https://doi.org/10.1523/ jneurosci.4297-14.2015.

58. Kitchigina V.F., Butuzova M.V. Theta activity of septal neurons during different epileptic phases: the same frequency but different significance? Exp Neurol 2009; 216(2): 449-458, https://doi.org/10.1016/j.expneurol.2009.01.001.

59. Rodriguez E., George N., Lachaux J.P., Martinerie J., Renault B., Varela F.J. Perception's shadow: long-distance synchronization of human brain activity. Nature 1999; 397(6718): 430-433, https://doi.org/10.1038/17120.

60. Hurtado J.M., Rubchinsky L.L., Sigvardt K.A. Statistical method for detection of phase-locking episodes in neural oscillations. J Neurophysiol 2004; 91(4): 1883-1898, https:// doi.org/10.1152/jn.00853.2003.

61. Canolty R.T., Edwards E., Dalal S.S., Soltani M., Nagarajan S.S., Kirsch H.E., Berger M.S., Barbaro N.M., Knight R.T. High gamma power is phase-locked to theta oscillations in human neocortex. Science 2006; 313(5793): 1626-1628, https://doi.org/10.1126/science.1128115.

62. Axmacher N., Henseler M.M., Jensen O., Weinreich I., Elger C.E., Fell J. Cross-frequency coupling supports multiitem working memory in the human hippocampus. Proc Natl Acad Sci U S A 2010; 107(7): 3228-3233, https://doi. org/10.1073/pnas.0911531107.

63. Montgomery S.M., Buzsaki G. Gamma oscillations dynamically couple hippocampal $\mathrm{CA} 3$ and $\mathrm{CA} 1$ regions during memory task performance. Proc Natl Acad Sci U S A 2007; 104(36): 14495-14500, https://doi.org/10.1073/ pnas. 0701826104 .

64. Tort A.B., Kramer M.A., Thorn C., Gibson D.J., Kubota Y., Graybiel A.M., Kopell N.J. Dynamic cross-frequency couplings of local field potential oscillations in rat striatum and hippocampus during performance of a T-maze task. Proc Natl Acad Sci U S A 2008; 105(51): 20517-20522, https://doi. org/10.1073/pnas.0810524105.

65. Nacher V., Ledberg A., Deco G., Romo R. Coherent delta-band oscillations between cortical areas correlate with decision making. Proc Natl Acad Sci U S A 2013; 110(37): 15085-15090, https://doi.org/10.1073/pnas.1314681110.

66. Wulff P., Ponomarenko A.A., Bartos M., Korotkova T.M., Fuchs E.C., Bähner F., Both M., Tort A.B., Kopell N.J., Wisden W., Monyer $\mathrm{H}$. Hippocampal theta rhythm and its coupling with gamma oscillations require fast inhibition onto parvalbumin-positive interneurons. Proc Natl Acad Sci U S A 2009; 106(9): 3561-3566, https://doi.org/10.1073/ pnas. 0813176106 
67. Siegel M., Warden M.R., Miller E.K. Phase-dependent neuronal coding of objects in short-term memory. Proc Natl Acad Sci U S A 2009; 106(50): 21341-21346, https://doi. org/10.1073/pnas.0908193106.

68. Gregoriou G.G., Gotts S.J., Zhou H., Desimone R. High-frequency, long-range coupling between prefrontal and visual cortex during attention. Science 2009; 324(5931): 12071210, https://doi.org/10.1126/science.1171402.

69. Palva J.M. Phase synchrony among neuronal oscillations in the human cortex. J Neurosci 2005; 25(15): 3962-3972, https://doi.org/10.1523/jneurosci.4250-04.2005.

70. Palva J.M., Monto S., Kulashekhar S., Palva S. Neuronal synchrony reveals working memory networks and predicts individual memory capacity. Proc Natl Acad Sci U S A 2010; 107(16): 7580-7585, https://doi.org/10.1073/pnas.0913113107.

71. Holz E.M., Glennon M., Prendergast K., Sauseng P. Theta-gamma phase synchronization during memory matching in visual working memory. Neurolmage 2010; 52(1): 326-335, https://doi.org/10.1016/j.neuroimage.2010.04.003.

72. Shirvalkar P.R., Rapp P.R., Shapiro M.L. Bidirectional changes to hippocampal theta-gamma comodulation predict memory for recent spatial episodes. Proc Natl Acad Sci U S A 2010; 107(15): 7054-7059, https://doi.org/10.1073/ pnas.0911184107.

73. Tanninen S.E., Nouriziabari B., Morrissey M.D., Bakir R., Dayton R.D., Klein R.L., Takehara-Nishiuchi K. Entorhinal tau pathology disrupts hippocampal-prefrontal oscillatory coupling during associative learning. Neurobiol Aging 2017; 58: 151-162, https://doi.org/10.1016/j.neurobiolaging.2017.06.024.

74. Friston K.J. Another neural code? Neurolmage 1997; 5(3): 213-220, https://doi.org/10.1006/nimg.1997.0260.

75. Buzsáki G., Lai-Wo S.L., Vanderwolf C.H. Cellular bases of hippocampal EEG in the behaving rat. Brain Res 1983; 6(2): 139-171, https://doi.org/10.1016/0165-0173(83)90037-1.

76. Buzsáki G., Buhl D.L., Harris K.D., Csicsvari J., Czéh B., Morozov A. Hippocampal network patterns of activity in the mouse. Neuroscience 2003; 116(1): 201-211, https://doi. org/10.1016/s0306-4522(02)00669-3.

77. Soltesz I., Deschenes M. Low- and high-frequency membrane potential oscillations during theta activity in CA1 and CA3 pyramidal neurons of the rat hippocampus under ketamine-xylazine anesthesia. J Neurophysiol 1993; 70(1): 97-116, https://doi.org/10.1152/jn.1993.70.1.97.

78. Lisman J., Idiart M. Storage of $7+/-2$ short-term memories in oscillatory subcycles. Science 1995; 267(5203): 1512-1515, https://doi.org/10.1126/science.7878473.

79. Mormann F., Fell J., Axmacher N., Weber B., Lehnertz K., Elger C.E., Fernández G. Phase/amplitude reset and theta-gamma interaction in the human medial temporal lobe during a continuous word recognition memory task. Hippocampus 2005; 15(7): 890-900, https://doi.org/10.1002/ hipo.20117.

80. Sirota A., Montgomery S., Fujisawa S., Isomura Y., Zugaro M., Buzsáki G. Entrainment of neocortical neurons and gamma oscillations by the hippocampal theta rhythm. Neuron 2008; 60(4): 683-697, https://doi.org/10.1016/j. neuron.2008.09.014.

81. Tort A.B.L., Komorowski R., Eichenbaum H., Kopell N. Measuring phase-amplitude coupling between neuronal oscillations of different frequencies. J Neurophysiol 2010; 104(2): 1195-1210, https://doi.org/10.1152/jn.00106.2010.

82. Scheffer-Teixeira R., Belchior H., Caixeta F.V. Souza B.C., Ribeiro S., Tort A.B.L. Theta phase modulates multiple layer-specific oscillations in the CA1 region. Cereb Cortex 2011; 22(10): 2404-2414, https://doi.org/10.1093/ cercor/bhr319.

83. Schomburg E.W., Fernández-Ruiz A., Mizuseki K., Berényi A., Anastassiou C.A., Koch C., Buzsáki G. Theta phase segregation of input-specific gamma patterns in entorhinalhippocampal networks. Neuron 2014; 84(2): 470-485, https:// doi.org/10.1016/j.neuron.2014.08.051.

84. Tass P., Rosenblum M.G., Weule J., Kurths J., Pikovsky A., Volkmann J., Schnitzler A., Freund H.-J. Detection of $n: m$ phase locking from noisy data: application to magnetoencephalography. Phys Rev Lett 1998; 81(15): 32913294.

85. Belluscio M.A., Mizuseki K., Schmidt R., Kempter R., Buzsaki G. Cross-frequency phase-phase coupling between theta and gamma oscillations in the hippocampus. J Neurosci 2012; 32(2): 423-435, https://doi.org/10.1523/ jneurosci.4122-11.2012.

86. Zheng C., Zhang T. Alteration of phase-phase coupling between theta and gamma rhythms in a depression-model of rats. Cogn Neurodyn 2012; 7(2): 167-172, https://doi. org/10.1007/s11571-012-9225-x.

87. Xu X., Liu C., Li Z., Zhang T. Effects of hydrogen sulfide on modulation of theta-gamma coupling in hippocampus in vascular dementia rats. Brain Topogr 2015; 28(6): 879-894, https://doi.org/10.1007/s10548-015-0430-x.

88. Zheng C., Zhang T. Synaptic plasticity-related neural oscillations on hippocampus-prefrontal cortex pathway in depression. Neuroscience 2015; 292: 170-180, https://doi. org/10.1016/j.neuroscience.2015.01.071.

89. Ittner A.A., Gladbach A., Bertz J., Suh L.S., Ittner L.M. p38 MAP kinase-mediated NMDA receptor-dependent suppression of hippocampal hypersynchronicity in a mouse model of Alzheimer's disease. Acta Neuropathol Commun 2014; 2(1): 149, https://doi.org/10.1186/s40478-014-0149-z.

90. Quilichini P., Sirota A., Buzsaki G. Intrinsic circuit organization and theta-gamma oscillation dynamics in the entorhinal cortex of the rat. J Neurosci 2010; 30(33): 1112811142, https://doi.org/10.1523/jneurosci.1327-10.2010.

91. Szczepanski S.M., Crone N.E., Kuperman R.A., Auguste K.I., Parvizi J., Knight R.T. Dynamic changes in phase-amplitude coupling facilitate spatial attention control in fronto-parietal cortex. PLoS Biology 2014; 12(8): e1001936, https://doi.org/10.1371/journal.pbio.1001936.

92. Buzsáki G. Rhythms of the brain. Oxford University Press; 2006, https://doi.org/10.1093/acprof:oso/ 9780195301069.001.0001.

93. Buzsáki G., Mizuseki K. The log-dynamic brain: how skewed distributions affect network operations. Nat Rev Neurosci 2014; 15(4): 264-278, https://doi.org/10.1038/ nrn3687.

94. Knight R.T. Neuroscience: neural networks debunk phrenology. Science 2007; 316(5831): 1578-1579, https://doi. org/10.1126/science.1144677.

95. Haider B., McCormick D.A. Rapid neocortical dynamics: cellular and network mechanisms. Neuron 2009; 62(2): 171 189, https://doi.org/10.1016/j.neuron.2009.04.008.

96. Voytek B., D'Esposito M., Crone N., Knight R.T. A method for event-related phase/amplitude coupling. Neurolmage 2013; 64: 416-424, https://doi.org/10.1016/j. neuroimage.2012.09.023.

97. Lega B.C., Jacobs J., Kahana M. Human hippocampal theta oscillations and the formation of episodic memories. 
Hippocampus 2011; 22(4): 748-761, https://doi.org/10.1002/ hipo.20937.

98. Newman E.L., Gillet S.N., Climer J.R., Hasselmo M.E. Cholinergic blockade reduces theta-gamma phase amplitude coupling and speed modulation of theta frequency consistent with behavioral effects on encoding. J Neurosci 2013; 33(50): 19635-19646, https://doi.org/10.1523/jneurosci. 2586-13.2013.

99. Schack B., Weiss S. Quantification of phase synchronization phenomena and their importance for verbal memory processes. Biol Cybern 2005; 92(4): 275-287, https:// doi.org/10.1007/s00422-005-0555-1.

100. Fell J., Axmacher N. The role of phase synchronization in memory processes. Nat Rev Neurosci 2011; 12(2): 105-118, https://doi.org/10.1038/nrn2979.

101. Scheffer-Teixeira R., Tort A.B. On cross-frequency phase-phase coupling between theta and gamma oscillations in the hippocampus. Elife 2016; 5: e20515, https://doi. org/10.7554/elife.20515.

102. Markram H. Regulation of synaptic efficacy by coincidence of postsynaptic APs and EPSPs. Science 1997; 275(5297): 213-215, https://doi.org/10.1126/science. 275.5297.213.

103. Morimoto K., Fahnestock M., Racine R.J. Kindling and status epilepticus models of epilepsy: rewiring the brain Prog Neurobiol 2004; 73(1): 1-60, https://doi.org/10.1016/j. pneurobio.2004.03.009.

104. Dupont S., Van de Moortele P.F., Samson S., Hasboun D., Poline J.B., Adam C., Lehéricy S., Le Bihan D., Samson Y., Baulac M. Episodic memory in left temporal lobe epilepsy: a functional MRI study. Brain 2000; 123(Pt 8): 1722 1732, https://doi.org/10.1093/brain/123.8.1722.

105. Helmstaedter C. Effects of chronic epilepsy on declarative memory systems. Prog Brain Res 2002; 135: 439453, https://doi.org/10.1016/s0079-6123(02)35041-6.

106. Burgess N., Maguire E.A., O'Keefe J. The human hippocampus and spatial and episodic memory. Neuron 2002; 35(4): 625-641, https://doi.org/10.1016/s0896-6273(02) 00830-9.

107. Tulving E. Episodic memory: from mind to brain. Annu Rev Psychol 2002; 53(1): 1-25, https://doi.org/10.1146/ annurev.psych.53.100901.135114.

108. Lega B., Dionisio S., Bingaman W., Najm I., Gonzalez-Martinez J. The gamma band effect for episodic memory encoding is absent in epileptogenic hippocampi. Clin Neurophysiol 2015; 126(5): 866-872, https://doi.org/10.1016/j. clinph.2014.07.035.

109. O'Keefe J., Nadel L. The hippocampus as a cognitive map. Oxford, UK: Oxford University Press; 1978.

110. Komorowski R.W., Manns J.R., Eichenbaum H. Robust conjunctive item-place coding by hippocampal neurons parallels learning what happens where. J Neurosci 2009; 29(31): 9918-9929, https://doi.org/10.1523/jneurosci. 1378-09.2009.

111. Mankin E.A., Sparks F.T., Slayyeh B., Sutherland R.J., Leutgeb S., Leutgeb J.K. Neuronal code for extended time in the hippocampus. Proc Natl Acad Sci U S A 2012; 109(47): 19462-19467, https://doi.org/10.1073/ pnas.1214107109.

112. Kraus B.J., Robinson R.J., White J.A., Eichenbaum H., Hasselmo M.E. Hippocampal "time cells": time versus path integration. Neuron 2013; 78(6): 1090-1101, https://doi.org/10.1016/j.neuron.2013.04.015.
113. Kitamura T., Pignatelli M., Suh J., Kohara K., Yoshiki A., Abe K., Tonegawa S. Island cells control temporal association memory. Science 2014; 343(6173): 896-901, https://doi.org/10.1126/science.1244634.

114. Frank L.M., Brown E.N., Wilson M. Trajectory encoding in the hippocampus and entorhinal cortex. Neuron 2000; 27(1): 169-178, https://doi.org/10.1016/s0896-6273(00)00018-0.

115. Wood E.R., Dudchenko P.A., Robitsek R.J., Eichenbaum $\mathrm{H}$. Hippocampal neurons encode information about different types of memory episodes occurring in the same location. Neuron 2000; 27(3): 623-633, https://doi. org/10.1016/s0896-6273(00)00071-4.

116. Huxter J.R., Senior T.J., Allen K., Csicsvari J. Theta phase-specific codes for two-dimensional position, trajectory and heading in the hippocampus. Nat Neurosci 2008; 11(5): 587-594, https://doi.org/10.1038/nn.2106.

117. Mizuseki K., Sirota A., Pastalkova E., Buzsáki G. Theta oscillations provide temporal windows for local circuit computation in the entorhinal-hippocampal loop. Neuron 2009; 64(2): 267-280, https://doi.org/10.1016/j.neuron 2009.08.037.

118. Easton A., Douchamps V., Eacott M., Lever C. A specific role for septohippocampal acetylcholine in memory? Neuropsychologia 2012; 50(13): 3156-3168, https://doi. org/10.1016/j.neuropsychologia.2012.07.022.

119. Buzsáki G., Moser E.I. Memory, navigation and theta rhythm in the hippocampal-entorhinal system. Nat Neurosci 2013; 16(2): 130-138, https://doi.org/10.1038/nn.3304.

120. Siapas A.G., Lubenov E.V., Wilson M.A. Prefrontal phase locking to hippocampal theta oscillations. Neuron 2005; 46(1): 141-151, https://doi.org/10.1016/j.neuron.2005.02.028.

121. Jones M.W., Wilson M.A. Theta rhythms coordinate hippocampal-prefrontal interactions in a spatial memory task. PLoS Biology 2005; 3(12): e402, https://doi.org/10.1371/ journal.pbio.0030402.

122. Broggini A.C.S., Esteves I.M., Romcy-Pereira R.N., Leite J.P., Leão R.N. Pre-ictal increase in theta synchrony between the hippocampus and prefrontal cortex in a rat model of temporal lobe epilepsy. Exp Neurol 2016; 279: 232-242, https://doi.org/10.1016/j.expneurol.2016.03.007.

123. Arabadzisz D., Antal K., Parpan F., Emri Z., Fritschy J.-M. Epileptogenesis and chronic seizures in a mouse model of temporal lobe epilepsy are associated with distinct EEG patterns and selective neurochemical alterations in the contralateral hippocampus. Exp Neurol 2005; 194(1): 76-90, https://doi.org/10.1016/j.expneurol.2005.01.029.

124. Colom L.V., García-Hernández A., Castañeda M.T. Perez-Cordova M.G., Garrido-Sanabria E.R. Septohippocampal networks in chronically epileptic rats: potential antiepileptic effects of theta rhythm generation. $J$ Neurophysiol 2006; 95(6): 3645-3653, https://doi.org/10.1152/jn.00040.2006.

125. Dugladze T., Vida I., Tort A.B., Gross A., Otahal J. Heinemann U., Kopell N.J., Gloveli T. Impaired hippocampal rhythmogenesis in a mouse model of mesial temporal lobe epilepsy. Proc Natl Acad Sci U S A 2007; 104(44): 1753017535, https://doi.org/10.1073/pnas.0708301104

126. Marcelin B., Chauvière L., Becker A., Migliore M., Esclapez M., Bernard C. h channel-dependent deficit of theta oscillation resonance and phase shift in temporal lobe epilepsy. Neurobiol Dis 2009; 33(3): 436-447, https://doi.org/10.1016/j. nbd.2008.11.019

127. García-Hernández A., Bland B.H., Facelli J.C., Colom L.V. Septo-hippocampal networks in chronic epilepsy. 
Exp Neurol 2010; 222(1): 86-92, https://doi.org/10.1016/j. expneurol.2009.12.010.

128. Selkoe D.J. Toward a comprehensive theory for Alzheimer's disease. Hypothesis: Alzheimer's disease is caused by the cerebral accumulation and cytotoxicity of amyloid $\beta$-protein. Ann N Y Acad Sci 2006; 924(1): 17-25, https://doi.org/10.1111/j.1749-6632.2000.tb05554.x.

129. Palop J.J., Mucke L. Amyloid-beta-induced neuronal dysfunction in Alzheimer's disease: from synapses toward neural networks. Nat Neurosci 2010; 13(7): 812-818, https:// doi.org/10.1038/nn.2583.

130. Francis B.M., Kim J., Barakat M.E., Fraenkl S., Yücel Y.H., Peng S., Michalski B., Fahnestock M., McLaurin J., Mount H.T. Object recognition memory and BDNF expression are reduced in young TgCRND8 mice. Neurobiol Aging 2012; 33(3): 555-563, https://doi.org/10.1016/j. neurobiolaging.2010.04.003.

131. Kametani F., Hasegawa M. Reconsideration of amyloid hypothesis and tau hypothesis in Alzheimer's disease. Front Neurosci 2018; 12: 25-36, https://doi.org/10.3389/ fnins.2018.00025.

132. Gureviciene I., Gurevicius K., Mugantseva E., Kislin M., Khiroug L., Tanila H. Amyloid plaques show binding capacity of exogenous injected amyloid- $\beta$. J Alzheimers Dis 2016; 55(1): 147-157, https://doi.org/10.3233/jad-160453.

133. Didic M., Barbeau E.J., Felician O., Tramoni E., Guedj E., Poncet M., Ceccaldi M. Which memory system is impaired first in Alzheimer's disease? J Alzheimers Dis 2011; 27(1): 11-22, https://doi.org/10.3233/jad-2011-110557.

134. Lithfous S., Dufour A., Després O. Spatial navigation in normal aging and the prodromal stage of Alzheimer's disease: insights from imaging and behavioral studies. Ageing Research Reviews 2013; 12(1): 201-213, https://doi. org/10.1016/j.arr.2012.04.007.

135. Adler G., Brassen S., Jajcevic A. EEG coherence in Alzheimer's dementia. J Neural Transm 2003; 110(9): 10511058, https://doi.org/10.1007/s00702-003-0024-8.

136. Herrmann C., Demiralp T. Human EEG gamma oscillations in neuropsychiatric disorders. Clin Neurophysiol 2005; 116(12): 2719-2733, https://doi.org/10.1016/j.clinph. 2005.07.007.

137. van der Hiele K., Vein A.A., van der Welle A., van der Grond J., Westendorp R.G., Bollen E.L., van Buchem M.A., van Dijk J.G., Middelkoop H.A. EEG and MRI correlates of mild cognitive impairment and Alzheimer's disease. Neurobiol Aging 2007; 28(9): 1322-1329, https://doi.org/10.1016/j. neurobiolaging.2006.06.006.

138. Czigler B., Csikós D., Hidasi Z., Anna Gaál Z., Csibri E., Kiss E., Salacz P., Molnár M. Quantitative EEG in early Alzheimer's disease patients - power spectrum and complexity features. Int J Psychophysiol 2008; 68(1): 75-80, https://doi.org/10.1016/j.ijpsycho.2007.11.002.

139. Moretti D.V., Pievani M., Geroldi C., Binetti G., Zanetti O., Rossini P.M., Frisoni G.B. EEG markers discriminate among different subgroup of patients with mild cognitive impairment. Am J Alzheimers Dis Other Demen 2010; 25(1): 58-73, https://doi.org/10.1177/1533317508329814.

140. Caravaglios G., Castro G., Costanzo E., Di Maria G., Mancuso D., Muscoso E.G. Theta power responses in mild Alzheimer's disease during an auditory oddball paradigm: lack of theta enhancement during stimulus processing. J Neural Transm 2010; 117(10): 1195-1208, https://doi.org/10.1007/ s00702-010-0488-2.
141. Wang J., Fang Y., Wang X., Yang H., Yu X., Wang H. Enhanced gamma activity and cross-frequency interaction of resting-state electroencephalographic oscillations in patients with Alzheimer's disease. Front Aging Neurosci 2017; 9: 243, https://doi.org/10.3389/fnagi.2017.00243.

142. Schneider F., Baldauf K., Wetzel W., Reymann K.G. Behavioral and EEG changes in male 5xFAD mice. Physiol Behav 2014; 135: 25-33, https://doi.org/10.1016/j. physbeh.2014.05.041.

143. Goodman M.S., Kumar S., Zomorrodi R., Ghazala Z., Cheam A.S.M., Barr M.S., Daskalakis Z.J., Blumberger D.M., Fischer C., Flint A., Mah L., Herrmann N., Bowie C.R., Mulsant B.H., Rajji T.K. Theta-gamma coupling and working memory in Alzheimer's dementia and mild cognitive impairment. Front Aging Neurosci 2018; 10: 101, https://doi. org/10.3389/fnagi.2018.00101.

144. Goutagny R., Gu N., Cavanagh C., Jackson J., Chabot J.G., Quirion R., Krantic S., Williams S. Alterations in hippocampal network oscillations and theta-gamma coupling arise before $A \beta$ overproduction in a mouse model of Alzheimer's disease. Eur J Neurosci 2013; 37(12): 1896-1902, https://doi.org/10.1111/ejn.12233.

145. Scott L., Feng J., Kiss T., Needle E., Atchison K., Kawabe T.T., Milici A.J., Hajós-Korcsok E., Riddell D., Hajós M. Age-dependent disruption in hippocampal theta oscillation in amyloid- $\beta$ overproducing transgenic mice. Neurobiol Aging 2012; 33(7): 1481.e13-1481.e23, https://doi.org/10.1016/j. neurobiolaging.2011.12.010.

146. Seabrook G.R., Smith D.W., Bowery B.J., Easter A., Reynolds T., Fitzjohn S.M., Morton R.A., Zheng H., Dawson G.R., Sirinathsinghji D.J., Davies C.H., Collingridge G.L., Hill R.G. Mechanisms contributing to the deficits in hippocampal synaptic plasticity in mice lacking amyloid precursor protein. Neuropharmacology 1999; 38(3): 349-359, https://doi.org/10.1016/s0028-3908(98)00204-4.

147. Senechal Y., Kelly P.H., Dev K.K. Amyloid precursor protein knockout mice show age-dependent deficits in passive avoidance learning. Behav Brain Res 2008; 186(1): 126-132, https://doi.org/10.1016/j.bbr.2007.08.003.

148. Zhang X., Zhong W., Brankačk J., Weyer S.W., Müller U.C., Tort A.B., Draguhn A. Impaired theta-gamma coupling in APP-deficient mice. Sci Rep 2016; 6: 21948, https:// doi.org/10.1038/srep21948.

149. Armon C., Peterson G.W., Liwnicz B.H. Alzheimer's disease underlies some cases of complex partial status epilepticus. J Clin Neurophysiol 2000; 17(5): 511-518, https:// doi.org/10.1097/00004691-200009000-00011.

150. Amatniek J.C., Hauser W.A., DelCastilloCastaneda C., Jacobs D.M., Marder K., Bell K., Albert M., Brandt J., Stern Y. Incidence and predictors of seizures in patients with Alzheimer's disease. Epilepsia 2006; 47(5): 867872, https://doi.org/10.1111/j.1528-1167.2006.00554.x.

151. Braak H., Braak E. Evolution of the neuropathology of Alzheimer's disease. Acta Neurol Scand Suppl 1996; 165: 3-12, https://doi.org/10.1111/j.1600-0404.1996.tb05866.x.

152. Born H.A., Kim J.Y., Savjani R.R., Das P., Dabaghian Y.A., Guo Q., Yoo J.W., Schuler D.R., Cirrito J.R., Zheng H., Golde T.E., Noebels J.L., Jankowsky J.L. Genetic suppression of transgenic APP rescues hypersynchronous network activity in a mouse model of Alzeimer's disease. J Neurosci 2014; 34(11): 3826-3840, https://doi.org/10.1523/ jneurosci.5171-13.2014.

153. Chan J., Jones N.C., Bush A.I., O'Brien T.J., Kwan P. 
A mouse model of Alzheimer's disease displays increased susceptibility to kindling and seizure-associated death. Epilepsia 2015; 56(6): e73-e77, https://doi.org/10.1111/epi.12993.

154. Bird S.B., Orr P.G., Mazzola J.L., Brush D.E., Boyer E.W. Levofloxacin-related seizure activity in a patient with Alzheimer's disease: assessment of potential risk factors J Clin Psychopharmacol 2005; 25(3): 287-288, https://doi org/10.1097/01.jcp.0000162811.15066.8e.

155. Bernardi S., Scaldaferri N., Vanacore N., Trebbastoni A., Francia A., D'Amico A., Prencipe M. Seizures in Alzheimer's disease: a retrospective study of a cohort of outpatients. Epileptic Disord 2010; 12(1): 16-21.

156. Palop J.J., Mucke L. Network abnormalities and interneuron dysfunction in Alzheimer disease. Nat Rev Neurosci 2016; 17(12): 777-792, https://doi.org/10.1038/ nrn.2016.141.

157. Bezzina C., Verret L., Juan C., Remaud J., Halley H., Rampon C., Dahan L. Early onset of hypersynchronous network activity and expression of a marker of chronic seizures in the Tg2576 mouse model of Alzheimer's disease. PLoS One 2015; 10(3): e0119910, https://doi.org/10.1371/journal. pone. 0119910 .

158. Palop J.J., Chin J., Roberson E.D., Wang J., Thwin M.T., Bien-Ly N., Yoo J., Ho K.O., Yu G.Q., Kreitzer A., Finkbeiner S., Noebels J.L., Mucke L. Aberrant excitatory neuronal activity and compensatory remodeling of inhibitory hippocampal circuits in mouse models of Neuron 2007; 55(5): 697-711, https://doi.org/10.1016/j.neuron.2007.07.025.

159. Bero A.W., Yan P., Roh J.H., Cirrito J.R., Stewart F.R., Raichle M.E., Lee J.M., Holtzman D.M. Neuronal activity regulates the regional vulnerability to amyloid- $\beta$ deposition. Nat Neurosci 2011; 14(6): 750-756, https://doi.org/10.1038/nn.2801.

160. Cirrito J.R., Kang J.-E., Lee J., Stewart F.R., Verges D.K., Silverio L.M., Bu G., Mennerick S., Holtzman D.M. Endocytosis is required for synaptic activity-dependent release of amyloid- $\beta$ in vivo. Neuron 2008; 58(1): 42-51, https://doi. org/10.1016/j.neuron.2008.02.003.

161. Gallassi R. Epileptic amnesic syndrome: an update and further considerations. Epilepsia 2006; 47(s2): 103-105, https://doi.org/10.1111/j.1528-1167.2006.00704.x.

162. Vossel K.A., Beagle A.J., Rabinovici G.D., Shu H., Lee S.E., Naasan G., Hegde M., Cornes S.B., Henry M.L., Nelson A.B., Seeley W.W., Geschwind M.D., Gorno-Tempini M.L., Shih T., Kirsch H.E., Garcia P.A., Miller B.L., Mucke L. Seizures and epileptiform activity in the early stages of Alzheimer disease. JAMA Neurol 2013; 70(9): 1158, https://doi.org/10.1001/jamaneurol.2013.136.

163. Cretin B., Sellal F., Philippi N., Bousiges O., Di Bitonto L., Martin-Hunyadi C., Blanc F. Epileptic prodromal Alzheimer's disease, a retrospective study of 13 new cases: expanding the spectrum of Alzheimer's disease to an epileptic variant? J Alzheimers Dis 2016; 52(3): 1125-1133, https://doi. org/10.3233/jad-150096.

164. Chin J., Scharfman H.E. Shared cognitive and behavioral impairments in epilepsy and Alzheimer's disease and potential underlying mechanisms. Epilepsy Behav 2013; 26(3): 343-351, https://doi.org/10.1016/j.yebeh.2012.11.040.

165. Eichler S.A. E-I balance and human diseases from molecules to networking. Front Mol Neurosci 2008; 1: 2, https://doi.org/10.3389/neuro.02.002.2008.

166. Noebels J. A perfect storm: converging paths of epilepsy and Alzheimer's dementia intersect in the hippocampal formation. Epilepsia 2011; 52: 39-46, https://doi. org/10.1111/j.1528-1167.2010.02909.x.

167. Saito Y., Inoue T., Zhu G., Kimura N., Okada M., Nishimura M., Kimura N., Murayama S., Kaneko S., Shigemoto R., Imoto K., Suzuki T. Hyperpolarization-activated cyclic nucleotide gated channels: a potential molecular link between epileptic seizures and $A \beta$ generation in Alzheimer's disease. Mol Neurodegener 2012; 7: 50, https://doi. org/10.1186/1750-1326-7-50.

168. Varga E., Juhász G., Bozsó Z., Penke B., Fülöp L., Szegedi V. Abeta(1-42) enhances neuronal excitability in the CA1 via NR2B subunit-containing NMDA receptors. Neural Plast 2014; 2014: 1-12, https://doi.org/10.1155/2014/584314.

169. Irizarry M.C., Jin S., He F., Emond J.A., Raman R., Thomas R.G., Sano M., Quinn J.F., Tariot P.N., Galasko D.R., Ishihara L.S., Weil J.G., Aisen P.S. Incidence of new-onset seizures in mild to moderate Alzheimer disease. Arch Neurol 2012; 69(3): 368, https://doi.org/10.1001/archneurol.2011.830.

170. Scarmeas N., Honig L.S., Choi H., Cantero J., Brandt J., Blacker D., Albert M., Amatniek J.C., Marder K., Bell K., Hauser W.A., Stern Y. Seizures in Alzheimer disease: who, when, and how common? Arch Neurol 2009; 66(8): 992997, https://doi.org/10.1001/archneurol.2009.130.

171. Sarkis R.A., Willment K.C., Gale S.A., Dworetzky B.A. Recurrent epileptic auras as a presenting symptom of Alzheimer's disease. Front Neurol 2017; 8: 360, https://doi. org/10.3389/fneur.2017.00360.

172. Minkeviciene R., Rheims S., Dobszay M.B., Zilberter M., Hartikainen J., Fülöp L., Penke B., Zilberter Y., Harkany T., Pitkänen A., Tanila $H$. Amyloid beta-induced neuronal hyperexcitability triggers progressive epilepsy. J Neurosci 2009; 29(11): 3453-3462, https://doi.org/10.1523/ jneurosci.5215-08.2009.

173. Vogt D.L., Thomas D., Galvan V., Bredesen D.E., Lamb B.T., Pimplikar S.W. Abnormal neuronal networks and seizure susceptibility in mice overexpressing the APP intracellular domain. Neurobiol Aging 2011; 32(9): 1725-1729, https://doi.org/10.1016/j.neurobiolaging.2009.09.002.

174. Yener G.G., Başar E. Biomarkers in Alzheimer's disease with a special emphasis on event-related oscillatory responses. Suppl Clin Neurophysiol 2013: 62: 237-273, https://doi.org/10.1016/b978-0-7020-5307-8.00020-x.

175. Wang B., Meng L. Functional brain network alterations in epilepsy: a magnetoencephalography study. Epilepsy Res 2016; 126: 62-69, https://doi.org/10.1016/j. eplepsyres.2016.06.014. 